\title{
Detection of Anti-Helicopacter pylori IgG Antibody, Anti- GAD antibody, Anti-Beta islets cell in a sample of serum with type-2 Diabetes mellitus patients
}

\author{
Dunya F. Salloom* \\ Received 25, June, 2012 \\ Accepted 18, November, 2012
}

\begin{abstract}
:
We have investigated twenty five patients with type- 2 diabetes mellitus aged (35-60) years and fifteen healthy persons as control group to detect Anti-Helicobacter pylori IgG antibody. All studied groups were carried out to measure fasting blood sugar, anti- Glutamic acid decarboxylase (GAD), anti- $\beta$ islets cells antibody by IFAT, Anti- $H$. pylori IgG antibody by ELISA technique. There was significant elevation in the concentration of fasting blood sugar than in control group $(\mathrm{P}<0.05)$, the patients had negative results for anti-GAD antibody and anti- $\beta$ islets cells antibody, there were significant differences $(\mathrm{P}<0.05)$ of anti-H. pylori $\mathrm{IgG}$ antibody in $28 \%$ of patients had type- 2 diabetes than control group. This lead to suggestion that type -2 diabetes mellitus patients are more susceptible to $H$. pylori .
\end{abstract}

Key words: type-2 diabetes mellitus, Helicobacter pylori, metabolic disorder.

\section{Introduction:}

Type-2 diabetes mellitus patients are more prone to infection because of the impairment of their immune status. H. pylori is one of the common chronic infection worldwide [1]. The elements of the innate immune system, such as C-reactive protein may predict risk of developing type-2 diabetes mellitus [2].

In diabetic patients the frequency of non-ulcer, non-gastric dyspepsia is two time higher than in non-diabetics persons and strictly association with autonomic neuropathy, acting as a favoring factor occurrence and recurrence of gastrointestinal disease [3].

Many patients with diabetes have upper and lower gastrointestinal (GI) symptoms [4]. Infection with $H$. pylori had been linked with chronic atrophic gastritis [5]. The rate of $H$. pylori infection was similar between the type2 diabetic group with or without gastrointestinal symptoms [6]. $H$. pylori is common infection in diabetics who do not have metabolically controlled hyperglycemic and these are individuals who are colonized by $H$. pylori infection in the gastric antrum [7]. There was a significant association between $H$. pylori infection and type-2 diabetes mellitus [8]. Both the natural history of gastrointestinal symptoms and factor influencing symptoms in diabetes mellitus were unknown. Hence the aim of this study is to investigate the association of $H$. pylori infection in type- 2 diabetes mellitus.

\section{Materials and methods:}

The study included twenty five patients with type-2 diabetes mellitus aged (35-60) years without gastric intestinal infections and fifteen healthy blood donor taken as control group. The work were done in Private

\footnotetext{
*Biology Dept. - College of Science - University of Baghdad
} 
Medical Specialized Clinical Laboratory.

All studied group measured fasting blood sugar by Human company, Germany. Anti-H. pylori $\mathrm{IgG}$ were measured in present study by ELISA test from Euroimmune, Germany, anti- Glutamic acid decarboxylease (GAD) and anti- $\beta$ islets by IFAT from Euroimmune, Germany.

\section{Results and discussion:}

The results of present study showed that there was a significant elevation in the concentration of fasting blood sugar $(250 \pm 5.3) \mathrm{mg} / \mathrm{dl}$ than in control group $(92.8 \pm 1.5) \mathrm{mg} / \mathrm{dl}$ as shown in figure (1).

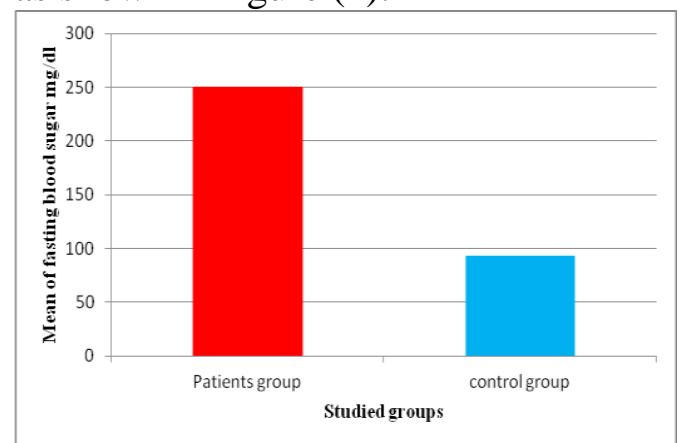

Fig. (1): Mean level of fasting blood sugar concentration $\mathrm{mg} / \mathrm{dl}$ in serum of women had diabetic mellitus and control group.

Where the results of anti-GAD antibody and anti- $\beta$ islets cell antibody by IFAT test of diabetes mellitus type2 patients serum were negative as in figure (2 and 3 ).

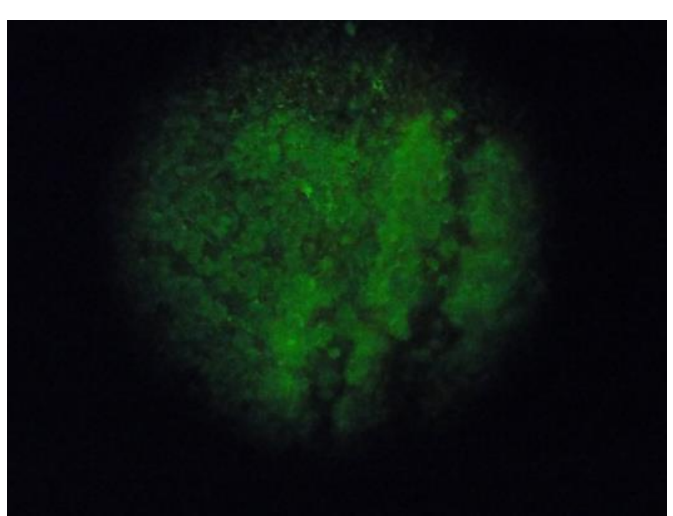

Fig. (2): Negative result of anti-GAD antibody in women sera had diabetic mellitus type-2

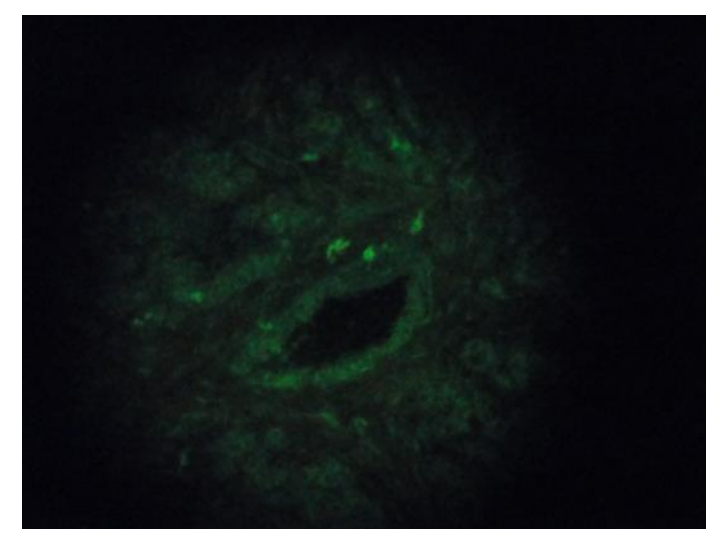

Fig. (3): Negative result of anti- $\beta$ islets cell antibody in women sera had diabetic mellitus typ-2

The demographic study showed that $7(28 \%)$ patients with diabetic mellitus type- 2 had sero positive results of $H$. pylori compared to control group $0 \%$, as in figure (4).

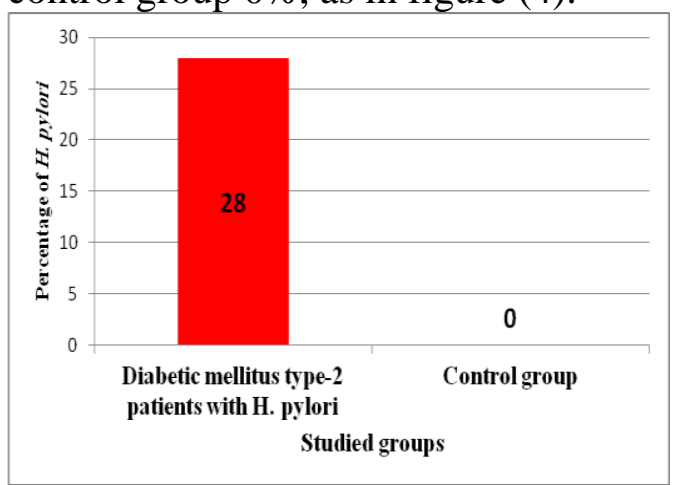

Fig. (4): Sero positive of $H$. pylori in sera of studied groups 
The result of the present study showed no significant differences ( $\mathrm{p}>$ 0.05 ) between sero positive samples of $H$. pylori and patient's age, while there were significant differences $(\mathrm{P}<0.05)$ in compare with sex, the male had showed high percentage.

In a study they found the association between diabetic mellitus type-2 patients and peptic ulcer caused by $H$. pylori. Diabetic mellitus related gastrointestinal motor dysfunction is common and affect the esophagus, stomach and lower GI tract, there are several pathogenic mechanisms may involve in these GI symptoms, such as autonomic neuropathy, diabetic peripheral neuropathy [9].

Infection with $H$. pylori has been linked with chronic atrophic gastritis in Diabetic mellitus [5]. H. pylori-related disease are associated with male gender in adult, this predominance of $H$. pylori is not apparent in children [10]. Other study showed that the rate of $H$. pylori infection in Hong Kong Chinese subjects with diabetic mellitus type-2 around $50 \%$, similar to control subjects [6], while the other showed higher frequency of $H$. pylori infection in dyspeptic patients affected with diabetic mellitus type-2 than in nondiabetes subject [3].

There was higher prevalence of H. pylori infection in obese diabetic patients $23.6 \%$ than the non-diabetic subject $11.8 \%$, there were different symptoms such as gastrointestinal, chronic bronchitis, nausa, anemia, abdominal pain, diarrhea and vomiting were common in diabetic patients with H. pylori [1].

Other reported that the prevalence of $H$. pylori infection in diabetic mellitus type- 2 range from 30 $78 \%$ [11]. The variability in the prevalence rates may be related to the epidemiology distribution of $H$. pylori, it had been speculated that the alteration in glucose metabolism may promote $H$. pylori colonization [12]. The present study showed that there was association between $H$. pylori infection in patients had diabetic mellitus type-2, these finding are generally explained by the impairment of cellular and humeral immunity in diabetic, by reduction of both gastrointestinal motility and acid secretion and by the effect of a higher secretion of proinfammatory cytokines attributable to $H$. pylori gastric infection $[6,7,13]$.

In a study they found that patients with type -2 diabetic mellitus had $H$. pylori $61 \%$ of the patients [14]. Other showed that diabetic mellitus are more prone and ar risk to a quire $H$. pylori infection, therefore proper monitoring of blood glucose level and screening for $H$. pylori infection are effective preventive measures for this life threatening infection [15]. There was association between $H$. pylori and insulin resistance [16].

$H$. pylori seropositivity and dyspeptic symptoms were similar in type -2 diabetic mellitus, although $H$. pylori infection when present in diabetics appears to influence glycemic status, the mechanism of which remains largely unknown [17].

The presence of $H$. pylori infection increased the risk of gastrointestinal cancer in diabetics and this is because hyperglycemia may be an effect modifying factor that promotes the carcinogenic effects of $H$. pylori in gastric mucosa [18].

\section{References}

1. Bener, A.; Uduman, S.A. and Ameen, |A. 2002. Prevalence of Helicobcter pylori infection. J. Communicable Dis., 34:179-184.

2. Crook, M.2004. Type-2 diabetes mellitus: a disease of the innate immune system. Diabetic Medicine, 21:203-207. 
3. Genritle, S.; Turco, S.; Oliviero, B. and Torella, R.1998. The role of autonomic neuropathy as a risk factor of Helicobacter pylori infection in dyspeptic patients with type-2 diabetes mellitus. Diabetes Research and clinical practice,42(1):41-48.

4. Rothstein, R.D. 1990. Gastrointestinal motility disorders in diabetes mellitus. Am. J. Gastronterol, 85:782-783.

5. Parsonnet, R.D.; Friedman, G.; Vandersteen, D.1991.

Helicobacter pylori infection and risk of gastric carcinoma. New. Eng. J. Med., 325:1127-1131.

6. Gary, T.C.; Francis, K.; WingBun, C. and etal. 2001. Helicobacter pylori infection in Chinese subject with type-2 diabetes. Endocrain research, 27(1):171-177.

7. Bytzer, P.; Talley, N.J.; Leemon, M. 2002. Gastrointestinal symptoms in diabetes mellitus are associated with poor glycemic control and diabetic complication. Am. J. Gastronterol., 97:604-611.

8. Bener, A.; Micallef, R.; Affifi, M. 2007. Association between type- 2 diabetes mellitus and Helicobacter pylori infection. Turkish J. Gastronetol., 18(4):225-229.

9. Kim, J.; Park, H.; Young, S. 2010. Diabetic factor associated with gastrointestinal symptoms in patients with type-2 diabetes. World J. Gastroentrol., 16(14):1782-1787.

10. Martel, C. and Parsonnet, J. 2006. Helicobacter pylori infection and gender; a metaanalysis of population-based prevalence survey. Digestive Dis. Sci., 51(12):910-915.

11. Anastosis, R. and Goutases, C. 2002. Helicobacter pylori infection in diabetic patients. Prevalence and endoscopic finding. Eur. J. Inter. Med., 13:376-379.

12. Perdichizzi, G.; Bottari, M. and Pallio, S. 1996. Gastric infection by $H$. pylori and antral gastritis in hyperglycemic obese and diabetic subject. New Microbiol., 19:149154.

13. Murray, L.J.; Bamford, K.B.; Oreilly, D.P. 1995. Helicobacter pylori infection relation with cardiovascular risk factor and social factor. Br. Heart. J., 74:497501.

14. Demir, M.; Gokturk, H. and Ozturk, N. A. 2008. Helicobacter pylori prevalence in diabetic mellitus patients with dyspeptic symptoms and its relationship to glycemic control and late complication. Dig. Dis. Sci, 53:2646 - 2649.

15. Devrajani, B.; Shah, S. and Soomro, A. 2010. Type - 2 diabetic mellitus: A risk factor for Helicobacter pylori infection: A hospital based case - control study. Int. J. Diabetes, 30(1): 22 28.

16. Gen, R.; Demir, M. and Ataseven, H. 2010. Effect of Helicobacter pylori eradication on insulin resistance, serum lipid and low grade inflammation. South Med. J., 103: 190 - 196.

17. Nicholas, C.; Emmanuei, C. and Brown, N. 2008. Helicobacter pylori seropositivity in Nigerians with type -2 diabetic mellitus. Inter. J. Trop. Med., 4(2): 217 222.

18. Marimthu, S.; Vijaragavan, P. and Moysich, K. 2011. Diabetic mellitus and gastric carcinoma. J. Carcinog., 10: 30 - 35 . 


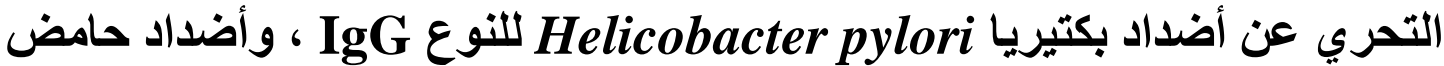
الكلوتاميك ، وأضداد خلايا جزر بيتا في عينة من مصول مرضى مصابين بداء السكري النمط الثاني عزئ مين

$$
\text { دنيا فريل سلومث* }
$$

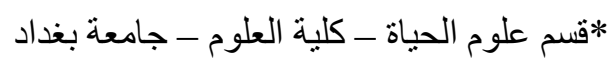

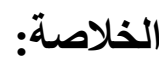

تم أخذ خمسة وعشرون عينة مصل دم لأثخاص مصابين بداء السكري النمط الثاني تتراوح أعمار هم ما بين

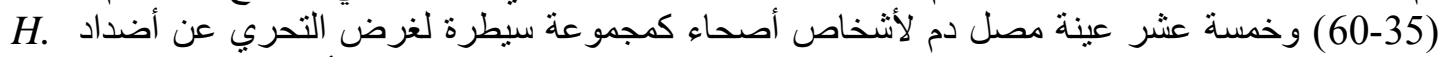
pylori

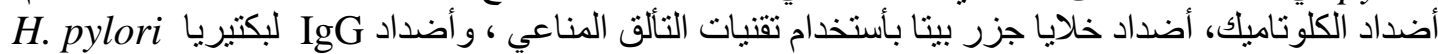

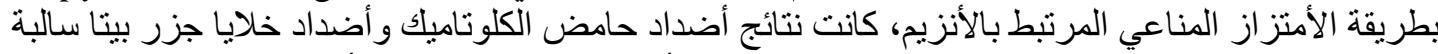

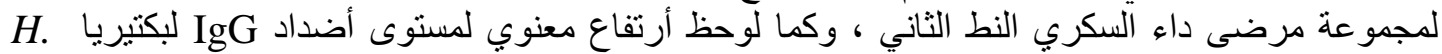
و pylori

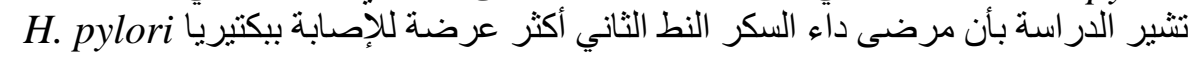

